\title{
Tracking the railway line in-service behaviour through metallurgical and mechanical property characterisation
}

\author{
A Mwamba ${ }^{1,2}$, A Mabeba ${ }^{1,3}$, J Moema $^{1.3}$, M Phasha $^{1}$ \\ ${ }^{1}$ Mintek, Johannesburg, South Africa \\ ${ }^{2}$ DST/NRF Centre of Excellence in Strong Materials at the University of the Witwatersrand, Johannesburg, South Africa \\ ${ }^{3}$ University of Pretoria \\ Email:alainm@mintek.co.za
}

\begin{abstract}
Wear, contact-impact, fatigue and corrosion properties are important factors initiating rail track degradation and are composition dependent. This work focuses on the effect of chromium content on the metallurgical and mechanical properties of the the rail steels. Two medium steel railway tracks differing in their chromium content, alloy MS02 with $0.02 \mathrm{wt} \% \mathrm{Cr}$ and alloy MS03 containing 0.72 $\mathrm{wt} \% \mathrm{Cr}$, were characterised in order to predict their in-service performance as a function of their chemical composition.

The microstructural analysis revealed in MS02 a relatively coarser grain size, consisting of pearlite and grain boundary ferrite. MS03 showed a fully pearlitic structure with no grain boundary ferrite. The average distance between cementite lamella in rail MS03 is shorter than that in MS02. The Rockwell C hardness values of MS02 were lower than those of MS03 which is in agreement with the microstructural analysis. As expected, a finer pearlitic structure observed in rail MS03 resulted in a superior tensile and impact properties as compared to MS02.

These data indicate that MS03 with a fully pearlitic structure gives a better wear resistance and higher strength than MS02 and, it is anticipated to give a better corrosion and oxidation resistance due to higher chromium content.
\end{abstract}

Keywords: Rail track, steel, microstructure, pearlite, SEM, mechanical properties

\section{Introduction}

Steel is one of the most researched material due to its economic impact in most countries. This role is enormous when one considers the numerous steel applications in the daily life. Among these applications is the use of steel in transport as railway track. To date, the chemical, mechanical and corrosion properties of the steel as railway track are well established and minimum performance requirements are well known. Thus, every time a new composition is developed, laboratory characterisations and field trials are needed to assess the properties of the new steel candidate against those of standard steel compositions with known properties and performance.

Generally the railway steel is characterised by the microstructure, tensile, hardness and wear resistance. In addition to the property dependence on the phase present in the microstructure, the hardness also depends on the grain size.

Characterisation of rail steel is also a function of the targeted properties. Asitha et al. ${ }^{1}$ have characterised the head-hardened rail steel in terms of cyclic plasticity response and microstructure for improved material modelling to confirm the impact of the rail shape on material inhomogeneity which impact, in turn, the rolling contact fatigue behaviour. In another study, Ma et $\mathrm{al}^{2}$ have shown the dependence of rail wear on the different slip ratio conditions during the wheel/rail contact fatigue. Other studies are focusing on the impact of corrosion properties on the wear and fatigue performance of rail steel. ${ }^{3-4}$
The need for corrosion-resistant steel has led to the painting of rail steel to prolong its life, a solution which is not practical for rail steel. In this regard, weathering or corten steels were developed to eliminate the need for coating ${ }^{8}$ and significant research activities are focused in this area. ${ }^{4,7}$

Railway steels are generally pearlitic. The rail head surface operates under abrasive conditions supplied by the railway wheel. Research has shown that by maximizing the hardness of the pearlitic structure, the wear rate is minimised in both laboratory and field tests. ${ }^{9,10}$ It was also found that the wear resistance increases with decreasing inter-lamellar spacing. ${ }^{10}$

Available data in the literature indicate that in the past 50 years the railways and rail manufacturers have improved rail performance by increasing hardness from $248 \mathrm{HB}$ to more than $400 \mathrm{HB}$. The historical path followed in the development of premium grade (high-performance) steel metallurgy is illustrated in Figure 1. ${ }^{11}$

The major alloying elements in steel is carbon (C). Carbon increases the volume fraction of hard phases in steel and, consequently, the hardness. It also influences the mechanical properties through the volume fraction of cementite and the content of pearlite. Alloying additions such as $\mathrm{Si}, \mathrm{Cr}, \mathrm{Ni}$ and $\mathrm{Mn}$ are added to increase the hardenability, i.e. these alloying elements delay the formation of softer phases. ${ }^{12}$ Manganese, for instance, influences the temperature decrease of the eutectoid reaction and the fineness of pearlite lamellae, that is, the reduction in the inter-lamellar distance. ${ }^{13}$ 


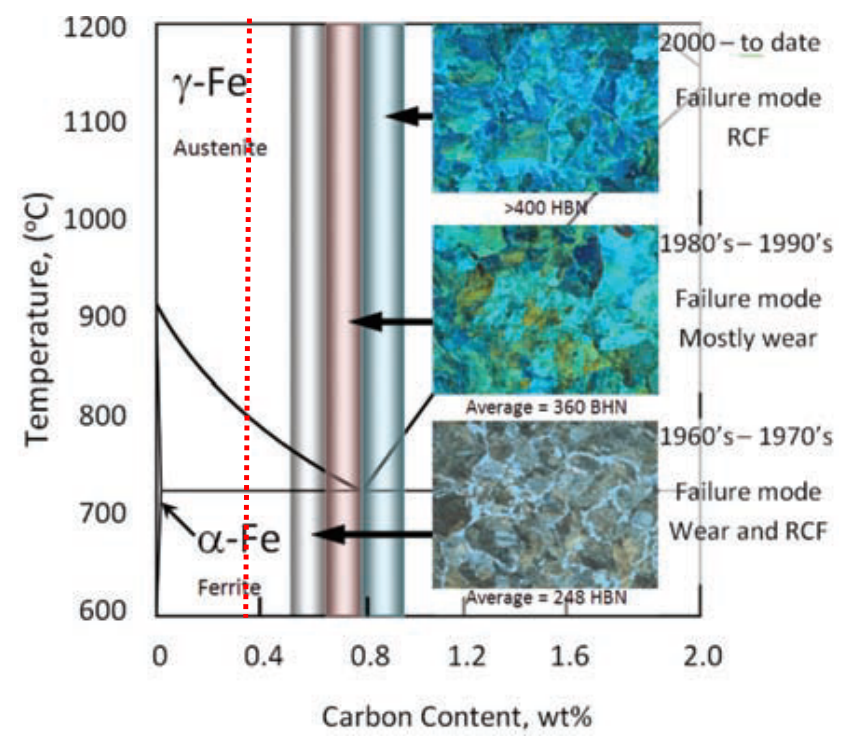

Figure 1: Evolution of rail steel metallurgies, hardness levels, and failure modes in the past 50 years ${ }^{11}$

In this work, metallurgical characterisation and mechanical testing were performed on two (2) railway track steel alloys.

\section{Experimental procedure}

\subsection{Visual examination}

All the railway track samples were visually examined for surface defects and weighed to determine their mass. The dimensions were measured with a digital calliper to confirm their sizes against the reference. ${ }^{12}$

\subsection{Chemical analysis}

Spark emission spectrometry was performed on the cross sectioned railway track samples according to ASTM E350-18. ${ }^{13}$ The samples were ground to remove rust, scale and other contaminants to reveal the metallic surface for analysis. The spectrometer analysis was programmed for low alloy steel and was calibrated using low carbon steel standard. Three spark analyses were performed on each sample and the results were averaged.

\subsection{Microstructural analysis}

Macro-etching, also referred to as deep etching, was performed on the traverse section of the two railway track samples according ASTM E340. ${ }^{14}$ A macrostructural examination at low magnifications was performed to reveal the existence of any defects such as: cracks, pipe, centre voids, centre unsoundness, pinholes, porosity, white band, chill structure, dendritic structure, inclusions, hydrogen flakes, segregation, banding, grain size, and other discontinuities or defects such as laps and seams.

A $25 \mathrm{~mm}$ cross-section was removed from each samples for microstructural analysis using an optical microscope. The samples were ground and polished according to ASTM E3 -11(2017). ${ }^{15}$ The cross-sections were polished to $1 u \mathrm{~m}$ finish and etched with $2 \%$ Nital to study their microstructures. The microstructural analysis was performed near the rail head surface (point A) and towards the rail web at point $B$ as shown in Figure 2.
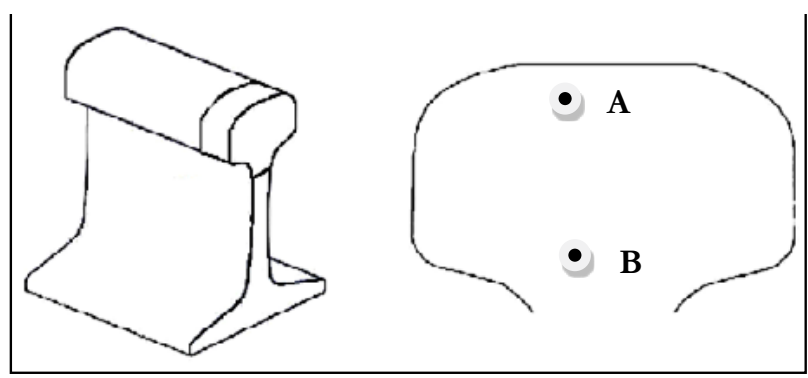

Figure 2: Railway schematic indicating positions where microstructural analysis was done

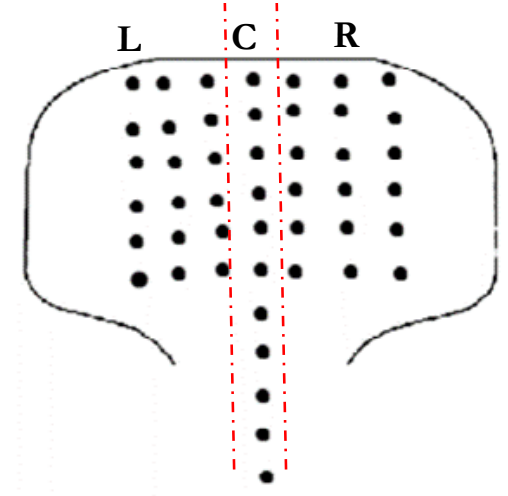

Figure 3: Rockwell C hardness traverse indentation map

Samples were removed near the rail head surface (position A in Figure 2) to study the inter-lamellar spacing using scanning electron microscopy. These samples were mounted and polished to analyse for pearlite inter-lamellar spacing.

\subsection{Hardness testing}

Rockwell C hardness measurements were performed at selected positions through the cross-sections of the two samples as per ASTM E18-19. ${ }^{16}$ The hardness measurements were done at $5 \mathrm{~mm}$ intervals according to schematic image in Figure 3. Figure 3 is divided into 3 sections, $\mathrm{C}, \mathrm{L}$, $\mathrm{R}$, where $\mathrm{C}$ represents the hardness measurements taken in the centre of the cross-sections, from the rail head surface until $100 \mathrm{~mm}$ depth, into the rail web. L represents the hardness taken to the left and $\mathrm{R}$ the hardness taken to the right.

\subsection{Tensile testing}

Tensile specimen were produced on each railway track sample according to ASTM E8-04. ${ }^{17}$ The tests were carried out at $2 \mathrm{~mm} /$ minute until $2 \%$ elongation where the rate was increased to $5 \mathrm{~mm} /$ minute. The yield stress of the specimens were measured from $0.2 \%$ offset yield stress. The elongation values were measured using an extensometer and from measuring the initial and final gauge length using a digital calliper to calculate the elongation $\%$.

\subsection{Charpy impact test}

Charpy impact specimens were tested at room temperature to assess the dynamic fracture behaviour of the railway steels. Charpy U-notch impact specimens were produced according to ASTME23A. ${ }^{18}$ However for the sake of this test, the U-notch was reduced from $5 \mathrm{~mm}$ to $2 \mathrm{~mm} .{ }^{19}$ The notch was made on the surface closest to the rail head surface. 
Table 1: Weights and Dimensions of the as-received railway track samples supplied for testing

\begin{tabular}{lcccc}
\hline \multirow{2}{*}{ Parameter } & \multicolumn{3}{c}{ Sample ID } \\
\cline { 2 - 5 } & \multicolumn{3}{c}{ MS02 } & MS03 \\
\cline { 2 - 5 } & Dimension $(\mathrm{mm})$ & Weight $(\mathrm{kg})$ & Dimension $(\mathrm{mm})$ & Weight $(\mathrm{kg})$ \\
\hline Total Length & & 18.96 & 304.35 & 18.04 \\
Rail Edge & 309.06 & & 72.34 \\
Rail Head & 71.74 & 74.08 & 17.06 \\
Rail Web & 73.29 & 149.87 & \\
Rail Bottom & 17.34 & & 172.04 \\
Rail Height & 149.88 & & \\
\hline
\end{tabular}

Table 2: Chemical composition of the railway track samples

\begin{tabular}{lcccccccccccc}
\hline Sample Identity & \multicolumn{10}{c}{} & \multicolumn{10}{c}{ Element (wt \%) } \\
\hline & $\mathbf{C}$ & Si & Mn & P & S & Cr & Ni & Ti & Al & Cu & V \\
\hline MS02 & 0.31 & 0.25 & 0.89 & 0.024 & 0.006 & 0.02 & 0.12 & 0.0025 & 0.0056 & 0.005 & 0.016 \\
MS03 & 0.35 & 0.43 & 0.39 & 0.013 & 0.011 & 0.72 & 0.23 & 0.0038 & 0.0037 & 0.030 & 0.002 \\
\hline
\end{tabular}

\section{Results and discussion}

\subsection{Dimensional measurements of the railway tracks}

The weight of each railway track sample was measured to be able to classify the type of the rail track. The dimensions and weight of the samples are summarised in Table 1, indicating that the dimensions are in agreement with the $60 \mathrm{~kg} / \mathrm{m}$ rail track profile. ${ }^{12}$

\subsection{Chemical analysis}

The compositions of the railway samples are presented in Table 2.

The carbon content indicates that the railways track samples were medium carbon steel as shown with a dotted red line in Figure 1. The chemical composition of MS02 is different from that of MS03.
MS02 showing lower silicon $(\mathrm{Si})$, chromium $(\mathrm{Cr})$ and nickel contents as compared to MS03. MS02 and a higher manganese (Mn) content. MS03 can be classified as medium carbon-high chromium steel. Table 2 gives the results of the spark emission spectrometry.

\subsection{Microstructural analysis}

The microstructures were studies near the rail head surface and towards the rail web, as indicated by position A and B in Figure 3. The micrographs are given at different magnifications, low magnification in Figure 4 and high magnification in Figure 5. Details of the microstructure are better seen at high magnification (Figure 5), showing the fineness and coarseness at the two different positions.
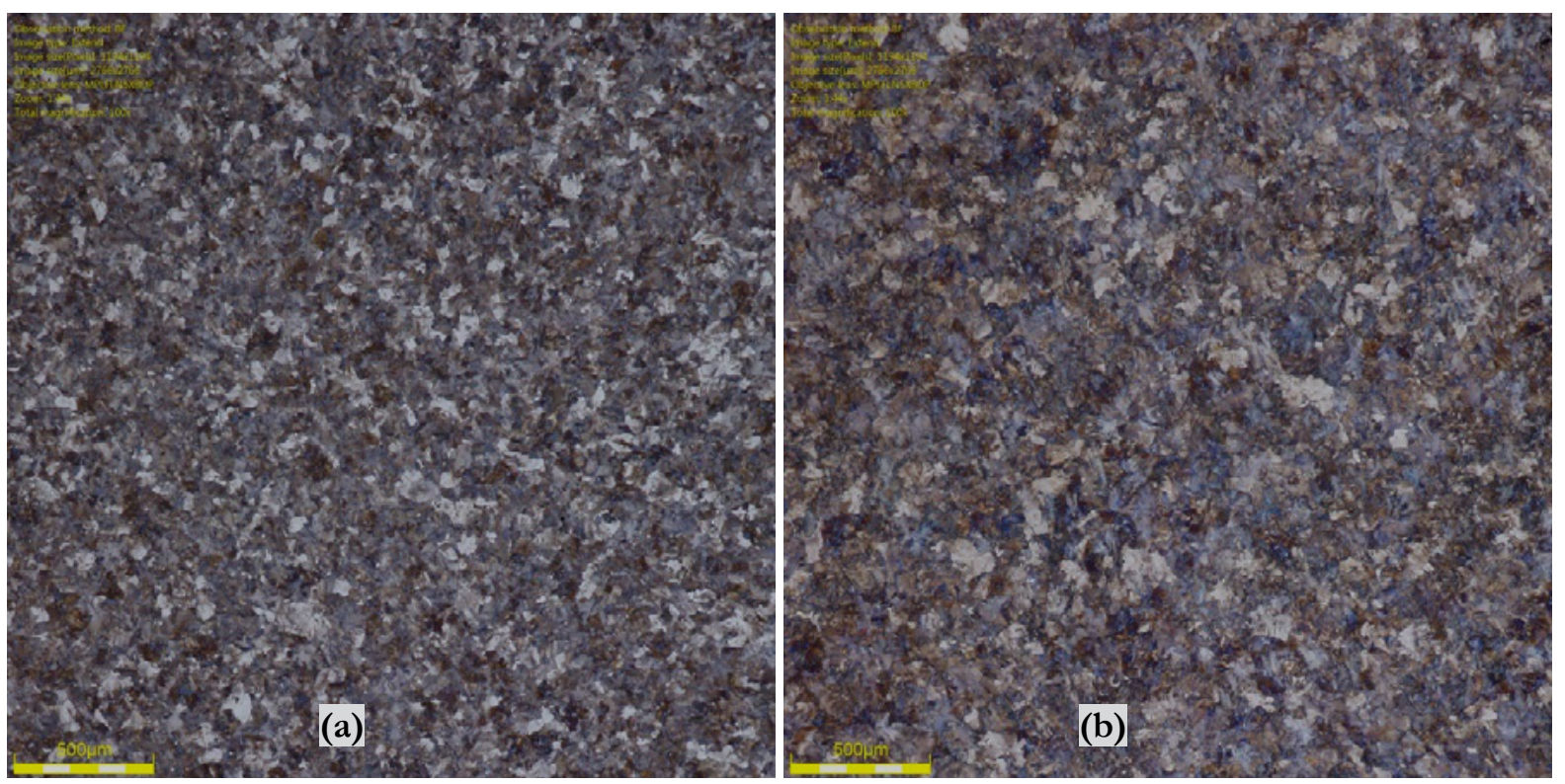

Figure 4: Microstructures of MS02 at 100X (low) magnification (a) near the rail head surface (Position A) and (b) at the centre (Position B) 

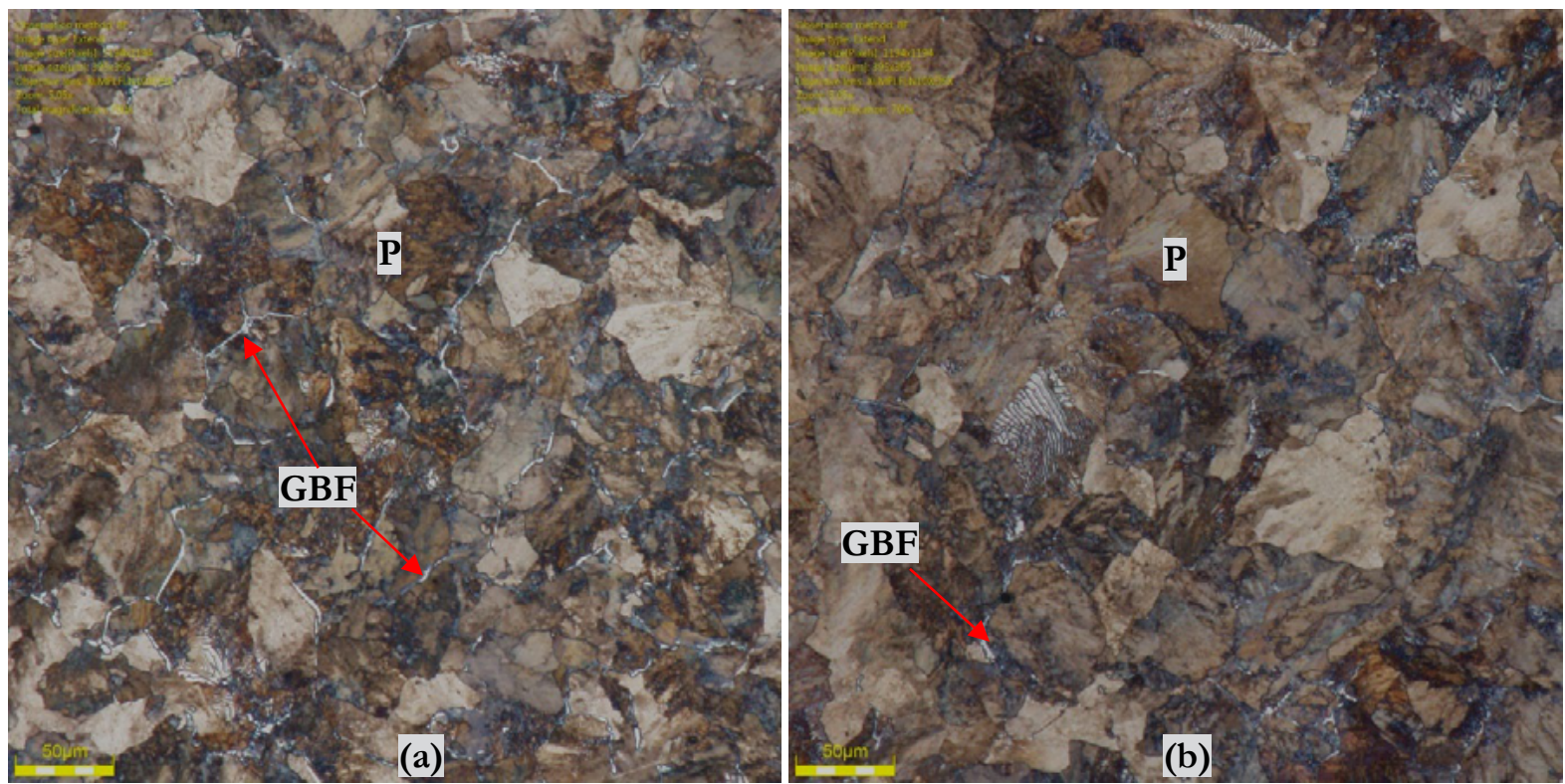

Figure 5: Microstructures of MS02 at high magnification (a) near the rail head surface (Position A) and (b) at the centre (Position B) showing pearlite $(\mathrm{P})$ and grain boundary pearlite $(\mathrm{GBF})$
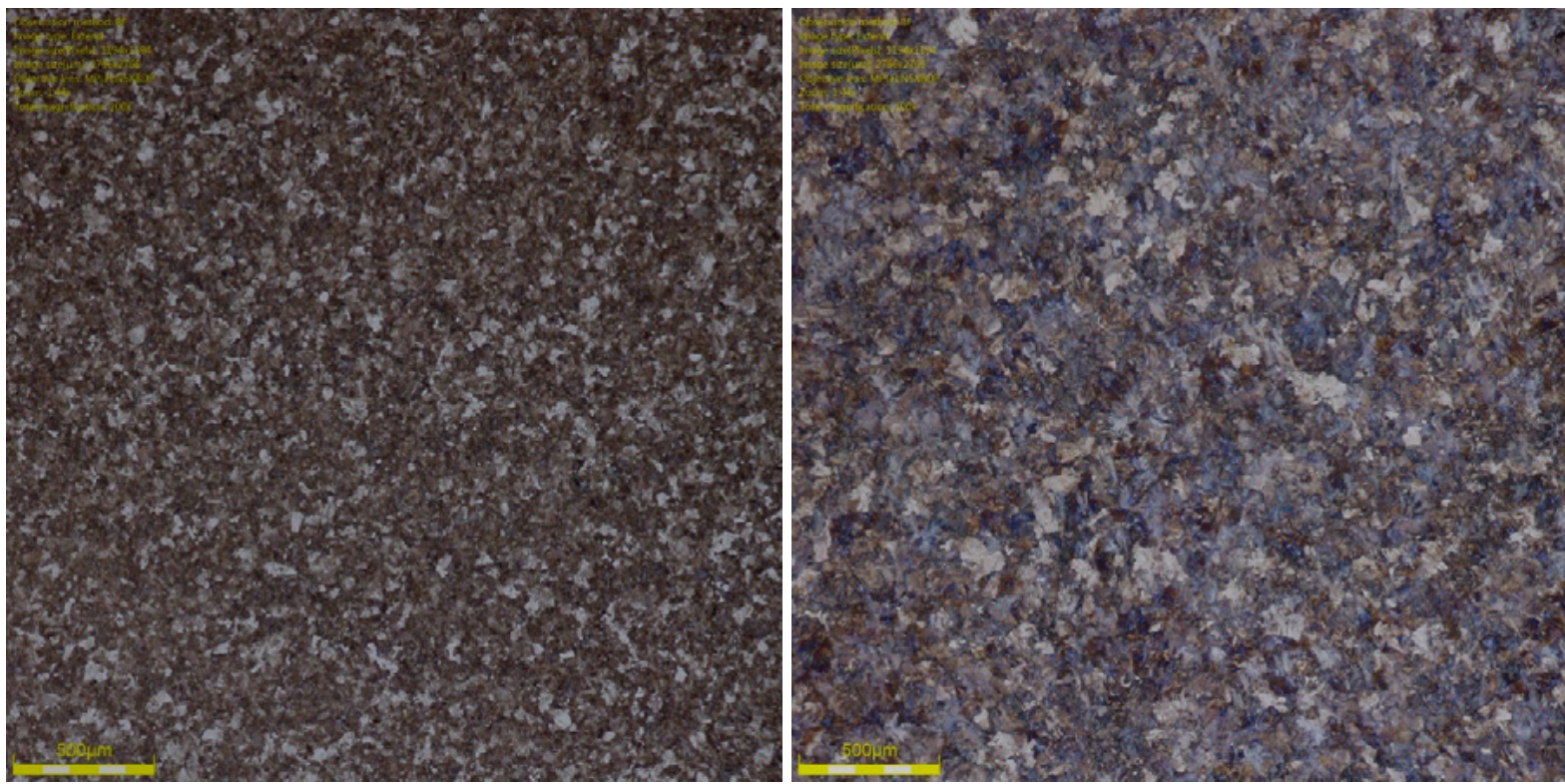

Figure 6: Microstructures of MS03 at 100X (low) magnification (a) near the rail head surface (Position A) and (b) at the centre (Position B)

The microstructures of MS03 is fully pearlitic as shown in Figures 6 and 7. In both cases, visually, the grains near the rail head surface (position A of Figure 3) were finer than those at centre (position B), see Figures 6 and 7.

\subsection{Scanning Electron Microscopy (SEM)}

With combined efforts of Gensamer et al, and Saltykov, it was possible to relate the mean linear intercept $\left(\mathrm{L}_{\text {mean }}\right)$ to the mean true spacing $\left(\lambda_{0}\right)$, it was found that $\mathrm{L}_{\text {mean }}=2 \lambda_{0} \cdot{ }^{14-16} \mathrm{~A}$ line $(\mathrm{L})$ of known length was drawn across a number of pearlite lamellae to determine inter-lamellar spacing. Figure 8 is an illustration of different possible measurements in a perfect lamella. The line (L) was divided by the number of lamellae intercepts to get the mean lineal intercept $\left(\mathrm{L}_{\text {mean }}\right)$, as shown in Figure 9. Table 3 summarises the mean inter-lamellar spacing results, it was found that MS03 has finer inter-lamellar spacing than MS02.

Table 3: Mean inter-lamellar spacing

\begin{tabular}{lccc}
\hline \multirow{2}{*}{ Property } & \multirow{2}{*}{ Symbol } & \multicolumn{2}{c}{ Values (nm) } \\
\cline { 3 - 4 } & & MS02 & MS03 \\
\hline Mean lineal intercept & $\mathbf{L}_{\text {mean }}$ & 277.9 & 87.3 \\
$\begin{array}{l}\text { Inter-lamellar spacing } \\
\text { (mean method) }\end{array}$ & $\lambda_{0}$ & 140.0 & 43.7 \\
\hline
\end{tabular}

\subsection{Hardness}

The Rockwell hardness values of measurements performed on L, C and $\mathrm{R}$ of the cross-sections (Figure 4), were averaged and are given in Table 4 and graphically presented in Figure 10. Table 4 indicates 

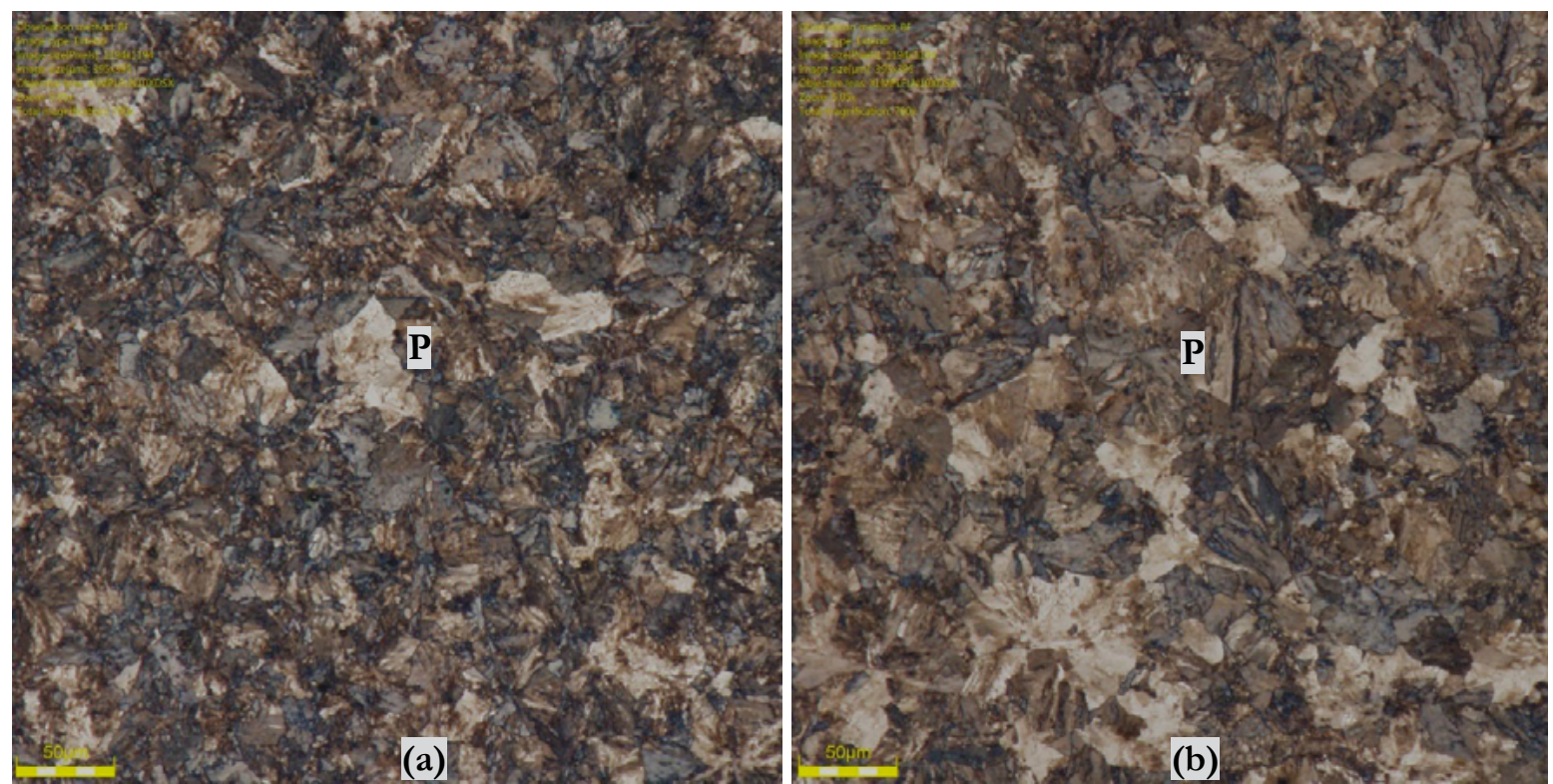

Figure 7: Microstructures of MS03 at high magnification (a) near the rail head surface (Position A) and (b) at the centre (Position B) showing pearlite $(\mathrm{P})$

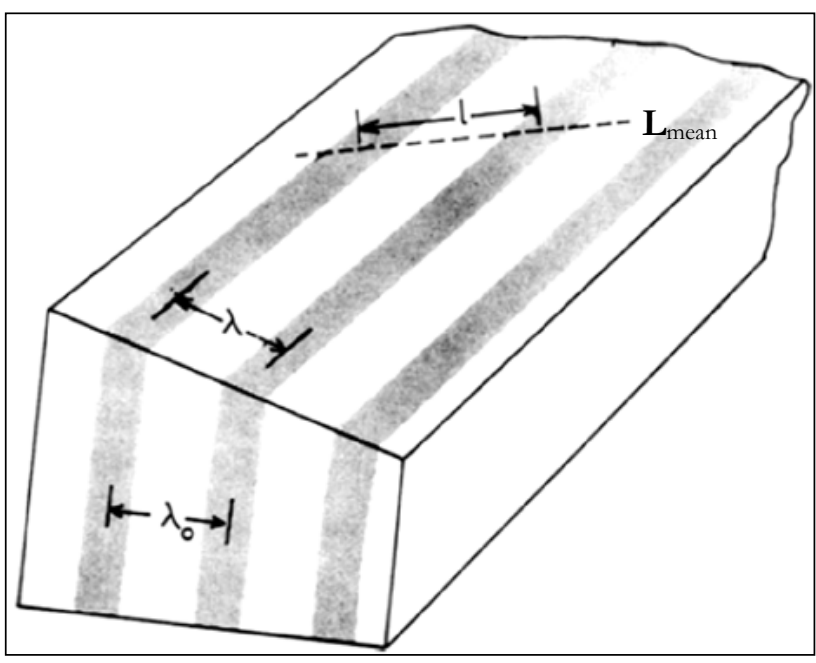

Figure 8: Schematic illustrations of various spacing in an ideal lamellar structure ${ }^{14-16}$

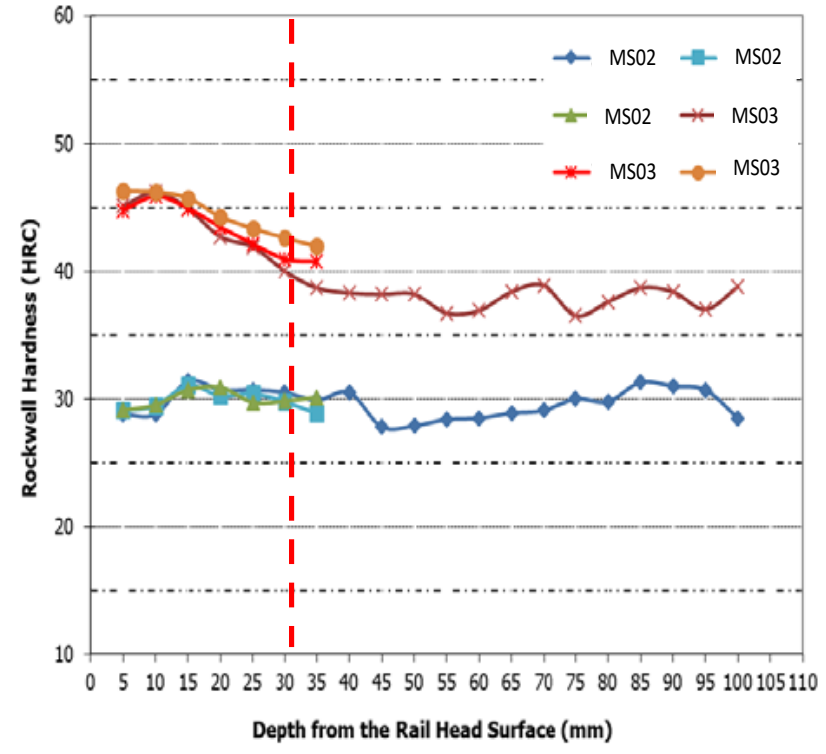

Figure 10: Graphical presentation of the hardness values of the railway cross-sections
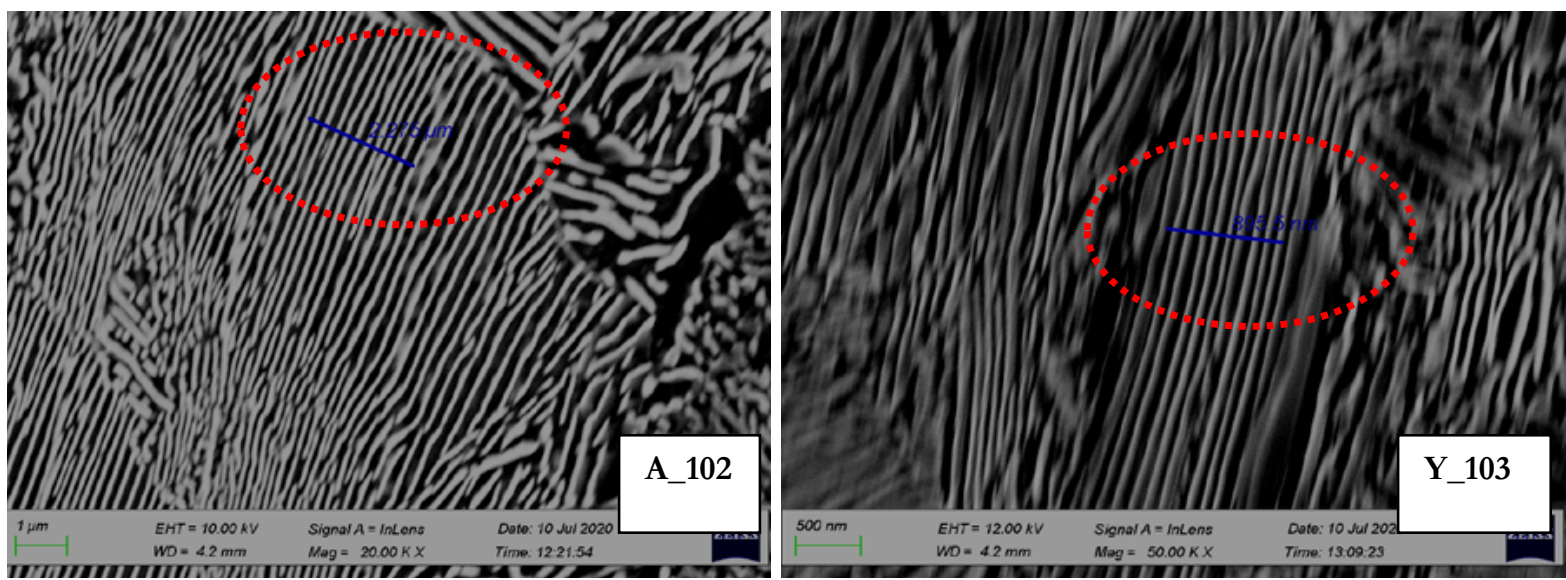

Figure 9: Scanning electron microscopy (SEM) images of MS02 and MS03 rail showing the measurement of the inter-lamellar spacing using the line intercept method 
Table 4: Rockwell C Hardness Results

\begin{tabular}{|c|c|c|c|c|c|c|c|c|c|c|c|c|c|c|}
\hline \multirow{3}{*}{$\begin{array}{l}\text { Depth from the } \\
\text { head surface } \\
(\mathrm{mm}) \\
\mathbf{5}\end{array}$} & \multicolumn{7}{|c|}{ MS02 } & \multicolumn{7}{|c|}{ MS03 } \\
\hline & \multicolumn{3}{|c|}{$\mathbf{L}$} & \multirow{2}{*}{$\frac{\mathbf{C}}{28.8}$} & \multicolumn{3}{|c|}{$\mathbf{R}$} & \multicolumn{3}{|c|}{$\mathbf{L}$} & \multirow{2}{*}{$\frac{\text { C }}{45.1}$} & \multicolumn{3}{|c|}{$\mathbf{R}$} \\
\hline & 26.1 & 30.2 & 31.0 & & 28.2 & 29.1 & 30.1 & 44.6 & 44.9 & 44.8 & & 45.9 & 46.2 & 46.7 \\
\hline 10 & 29.1 & 29.9 & 29.4 & 28.8 & 30.1 & 29.5 & 29.0 & 45.3 & 46.0 & 46.3 & 46.2 & 46.0 & 46.8 & 45.8 \\
\hline 15 & 31.2 & 31.2 & 30.8 & 31.4 & 31.1 & 30.7 & 30.3 & 44.5 & 45.6 & 44.7 & 44.9 & 45.0 & 46.1 & 46.1 \\
\hline 20 & 30.3 & 30.1 & 30.3 & 30.7 & 31.0 & 30.7 & 31.0 & 42.4 & 43.5 & 44.5 & 42.7 & 43.6 & 44.2 & 45.0 \\
\hline 25 & 30.0 & 31.1 & 30.1 & 30.7 & 30.0 & 29.6 & 29.6 & 40.6 & 42.6 & 43.2 & 41.9 & 41.8 & 43.4 & 44.9 \\
\hline 30 & 28.4 & 30.9 & 30.0 & 30.5 & 30.6 & 29.2 & 29.7 & 39.4 & 42.1 & 41.3 & 40.0 & 40.4 & 42.4 & 45.0 \\
\hline 35 & 28.2 & 29.2 & 29.2 & 27.5 & 31.2 & 29.8 & 29.4 & 39.4 & 40.8 & 42.0 & 38.7 & 40.3 & 41.9 & 43.7 \\
\hline 40 & - & - & - & 30.5 & - & - & - & - & - & - & 38.3 & - & - & - \\
\hline 45 & - & - & - & 27.8 & - & - & - & - & - & - & 38.2 & - & - & - \\
\hline 50 & - & - & - & 27.9 & - & - & - & - & - & - & 38.2 & - & - & - \\
\hline 55 & - & - & - & 28.4 & - & - & - & - & - & - & 36.7 & - & - & - \\
\hline 60 & - & - & - & 28.5 & - & - & - & - & - & - & 36.9 & - & - & - \\
\hline
\end{tabular}

Table 5: Tensile Properties

\begin{tabular}{lcccc}
\hline Specimen Identity & Thickness mm $\left(\mathbf{T}_{\mathbf{0}}\right)$ & $\begin{array}{c}\text { Yield stress (Offset 0.2 \%) } \\
(\mathbf{M P a})\end{array}$ & $\begin{array}{c}\text { Maximum Tensile Stress } \\
(\mathbf{M P a})\end{array}$ & $\begin{array}{c}\text { Measured } \\
\text { Elongation,\% }\end{array}$ \\
\hline MS02-1 & 6.35 & 585.3 & 955.3 & 18.22 \\
MS02-2 & 6.42 & 509.2 & 952.4 & 18.52 \\
MS02-3 & 6.37 & 513.8 & 969.5 & 17.36 \\
MS03-1 & 6.37 & 985.1 & 1448.7 & 16.96 \\
MS03-2 & 6.38 & 985.0 & 1444.5 & 16.72 \\
MS03-3 & 6.36 & 983.8 & 1476.3 & 17.56 \\
\hline
\end{tabular}

that the hardness values of MS02 are lower than that of MS03. This is in agreement with the microstructure observed for MS02 where a ferritic phase was observed on grain boundaries. The hardness values of MS02 closer to the rail head surface are around 30HRC. The hardness values of MS03 closer to the rail head surface are higher, about $45 \mathrm{HRC}$ and reduces slightly as the distance from the rail head is increased.

\subsection{Tensile testing}

The tensile strength and elongation of the specimens were measured at room temperature and the results are shown in Table 5 and the engineering stress vs engineering strain curves were plotted in Figure 11 where the test results of MS02-3 and MS03-2 were selected for railway sample MS02 and MS03 respectively. The

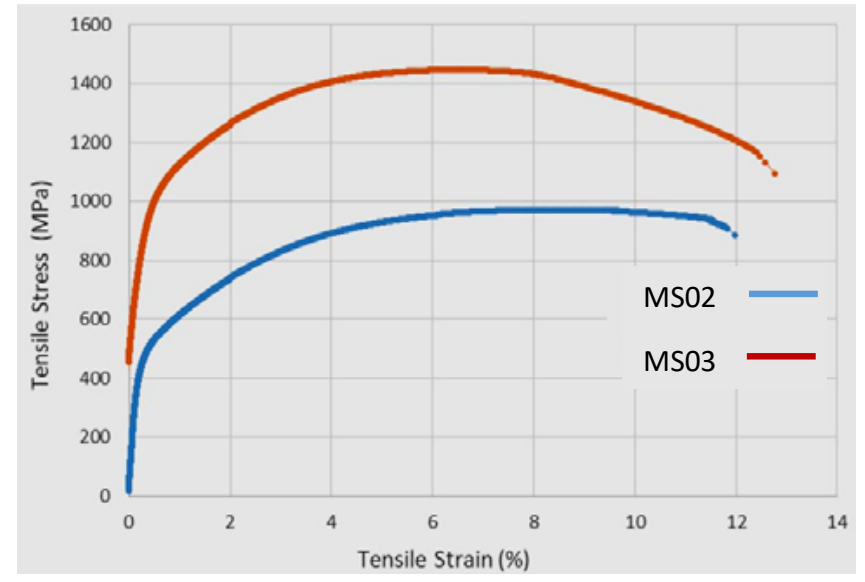

Figure 11: Tensile stress vs tensile strain

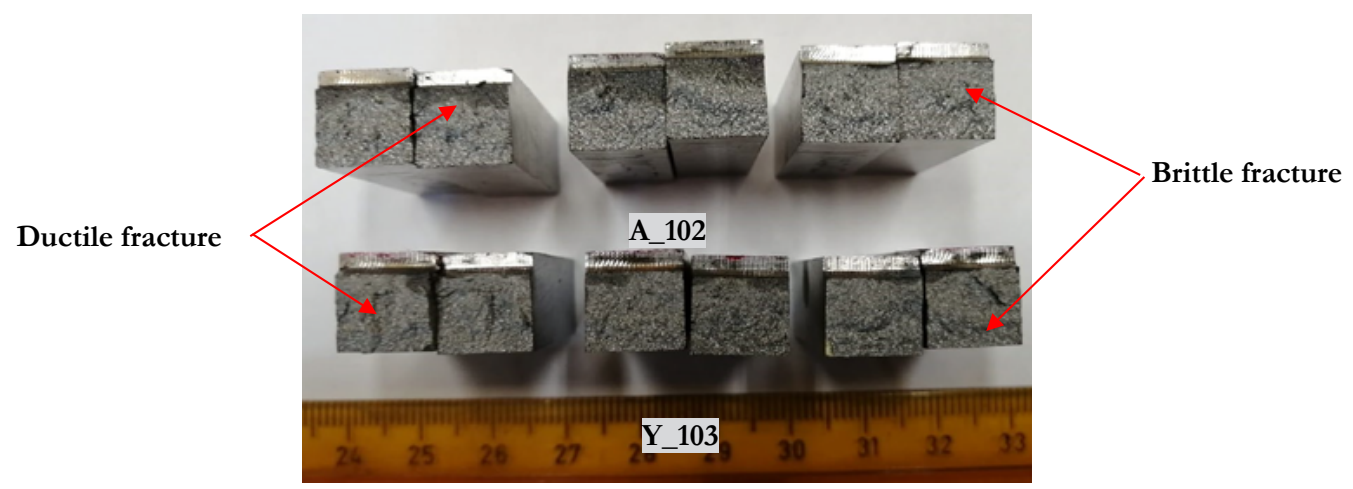

Figure 12: Macro photograph images of representative broken Charpy U-notch $(2 \mathrm{~mm})$ specimens for the rail samples showing a mixture of ductile and brittle failure mode 
Table 6: Charpy Impact test results at room temperature

\begin{tabular}{|c|c|c|}
\hline \multirow{2}{*}{ Charpy Impact test } & \multicolumn{2}{|c|}{ Energy, J } \\
\hline & MS02 & MS03 \\
\hline Test 1 & 16.0 & 17.4 \\
\hline Test 2 & 16.7 & 12.4 \\
\hline Test 3 & 12.4 & 19.9 \\
\hline Average & 16.3 & 18.6 \\
\hline Standard Deviation & 2.31 & 3.81 \\
\hline
\end{tabular}

$\mathrm{x}$-axis was plotted from the measured extensometer values during the test. The measured elongation values are shown in Table 5. The difference arises from the possible slipping of the extensometer that usually occurs during testing and the interface between the two fractures that is included in the measurement. MS03 shows superior tensile properties in terms of yield strength and maximum tensile strength.

\subsection{Charpy impact test}

Charpy impact test results are shown in Table 6. Three tests were conducted on both samples and two successful tests were averaged. Given the standard deviation of the measurement, the impact energy of MS03 was found to be similar to that of MS02, indicating the same toughness for MSO2 and MS03. One specimen out of each rail track showed lower impact value of $12 \mathrm{~J}$.

Figure 12 shows the macro photograph images of representative broken Charpy U-notch $(2 \mathrm{~mm})$ specimens of all the tested specimen. The large shiny grey region indicates a brittle fracture whereas the small darker grey shows ductile fracture. All the samples show both grey colours on their fracture surfaces.

\section{Conclusion}

The following conclusions drawn are based on the assessment of the supplied two railway track samples:

\section{Railway Track Sample MS02}

- The sample showed high temperature scaling and there was no apparent surface defects.

- The railway track can be classified as a medium carbon steel $0.31 \mathrm{wt} \% \mathrm{C}, 0.25 \mathrm{wt} \% \mathrm{Si}, 0.89 \mathrm{wt} \% \mathrm{Mn}$ and $0.02 \mathrm{wt} \% \mathrm{Cr}$.

- The grain size is coarser than that of $\mathrm{MS03}$ and their microstructures comprise of pearlite and grain boundary ferrite.

- Position A near the rail head surface, visually, show a finer grain size than position B towards the rail web.

- The Rockwell $\mathrm{C}$ hardness values near the rail head surface (Position A) are $\sim 30 \mathrm{HRC}$ and at position B are $\sim 28 \mathrm{HRC}$

- The hardness graph does not show a significant gradient, generally the hardness revolve around 28 - 30HRC.

- The average $0.2 \%$ offset yield stress and the ultimate tensile strength are 536.1 MPa and 959.1 MPa respectively.

- Charpy impact results reported an average of $16.3 \mathrm{~J}$.

Railway Track Sample MS03

- No apparent surface defects were observed on the surface
- The railway track can be classified as a medium carbon-high chromium steel - $0.35 \mathrm{wt} \% \mathrm{C}, 0.43 \mathrm{wt} \% \mathrm{Si}, 0.39 \mathrm{wt} \% \mathrm{Mn}$ and $0.72 \mathrm{wt} \% \mathrm{Cr}$.

- Their microstructures show to be fully pearlitic. Position A near the rail head surface show finer grain size than position B towards the rail web.

- The hardness values near the rail head surface (Position A) are $\sim 45 \mathrm{HRC}$ and at position B are $\sim 37 \mathrm{HRC}$.

- The hardness graph shows a gradient, the hardness values decreased as the distance from the rail head surface was increased.

- The average $0.2 \%$ offset yield stress and the ultimate tensile strength are 984.6 MPa and 1456.5 MPa respectively.

- Charpy impact results reported an average of $18.6 \mathrm{~J}$.

Overall, the two railway tracks are made of carbon-manganese steel (MS02 being medium C and MS03 being medium carbonhigh chrome) with pearlitic microstructure. MS03 with a finer grain structure and finer inter-lamellar spacing showed superior mechanical properties such as hardness and tensile. However, they showed a similar impact toughness.

\section{Future work}

Going forward, the following tests will be conducted:

- Wear tests

- Fatigue tests

- Corrosion tests

References

1. Asitha C. Athukorala, Dennis V. De Pellegrin, Kyriakos I.Kourousis, Characterisation of head-hardened rail steel in terms of cyclic plasticity response and microstructure for improved material modelling, Wear, pp 366-367(2016) 416-424.

2. L. Ma, C.G.He, X.J.Zhao, J.Guo, Y.Zhu, W.J.Wang, Q.Y.Liu and X.S.Jin, Study on wear and rolling contact fatigue behaviours of wheel/rail materials under different slip ratio conditions, Wear, pp 366-367(2016)13-26

3. R. Balasubramaniam, B. Panda, G. Dwivedi, A. P. Moon, S. Mahapatra, A. K. Manuwal, A. Bhattacharyya, K. Srikanth and R. K. Rathi, Alloy development of corrosion-resistant rail steel, Current Science, Vol. 100, No. 1, 2011), pp. 52-57

4. N.K.TewaryA.KunduR.NandiJ.K.SahaS.K.Ghosh, Microstructural characterisation and corrosion performance of old railway girder bridge steel and modern weathering structural steel, Corrosion Science 113, 2016, pp 57-63.

5. G.W. Ritter, William C. Mohr, C.D. Stuart, D.Y. Jeong and Y.H.Tang, Effects of Combined Corrosion and Fatigue on Rail Performance, https://eoncoat.com/wp-content/uploads/2016/09/arema.pdf, accessed on Febraury 12, 2021

6. M. Masoumi, E.A. Esheverri, A.P. Tschiptschin and H. Goldenstein, Improvement of wear resistance in a pearlitic rail steel via quenching and partitioning processing, Scientific Reports 9, Vol. 7454, pp

7. R. Heidersbach, Corrosion Performance of Weathering Steel Structures, TRANSPOKIAT/ON RESEARCH RECORD 1113, on http://onlinepubs.trb.org/Onlinepubs/trr/1987/1113/1113-004.pdf

8. Weathering steel: A guide to corten and the A/B equivalent, Origins \& Standards. https://www.azom.com/article.aspx?ArticleID=12974, accessed on June 7, 2021

9. G. Krauss, Steels - Processing, Structure, and Performance, Materials Park, OH: ASM International, 2005, pp. 281-295

10. A.P.G. ChavesD.M.A. CentenoM. MasoumiH. Goldenstein, Effect of the Microstructure on the Wear Resistance of a Pearlitic Steel, Materials Research, 2020; 23(2, DOI:10.1590/1980-5373-mr-2019-0605

11. R. Ordonez Olivares, C.I. Garcia, and F.C. Robles Hernandez, Metallurgy of high-carbon steels for railroad Applications, The Journal of The Southern African Institute of Mining and Metallurgy, Volume 113 February 2013 
12. Rail Track Material - Steel Rails and Trak-Lok®, Steel Sleeper Systems, www.libertyonesteel.com, accessed June 2020

13. ASTM E350-18, Standard Test Methods for Chemical Analysis of Carbon Steel, Low-Alloy Steel, Silicon Electrical Steel, Ingot Iron, and Wrought Iron, ASTM International, West Conshohocken, PA, 2018, www.astm.org .

14. ASTM E340: Standard Test Method for Macroetching Metals and Alloys, ASTM International, West Conshohocken, PA, 2018, www. astm.org .

15. ASTM E3-11(2017), Standard Guide for Preparation of Metallographic Specimens, ASTM International, West Conshohocken, PA, 2017, www.astm.org .
16. ASTM E18-19, Standard Test Methods for Rockwell Hardness of Metallic Materials, ASTM International, West Conshohocken, PA, 2019, www.astm.org

17. ASTM E8M, Test Methods for Tension Testing of Metallic Materials, ASTM International, West Conshohocken, PA, 2019, www.astm.org

18. ASTM - E23A, Standard Test Methods for Notched Bar Impact Testing of Metallic Materials, ASTM International, West Conshohocken, PA, 2019, www.astm.org .

19. G.T. Eavenson, The Effect of Copper on the Metallurgical, Mechanical and Fracture Properties of 0.90 Carbon Rail Steel, 2017

20. Acknowledgments

21. The authors would like to thank Mintek for the financial and technical support. 